\title{
Influence of Thermal Shrinkage on Protective Clothing Performance during Fire Exposure: Numerical Investigation
}

\author{
Ahmed Ghazy ${ }^{1}$ \\ ${ }^{1}$ Faculty of Engineering, Helwan University, Cairo, Egypt \\ Correspondence: Ahmed Ghazy, Faculty of Engineering, Ibrahim Abel Razik Street, Ain Shams E., 11718, Cairo, \\ Egypt. E-mail: ahmed.ghazy@usask.ca
}

Received: March 31, 2014 Accepted: May 8, 2014 Online Published: June 20, 2014

doi:10.5539/mer.v4n2p1

URL: http://dx.doi.org/10.5539/mer.v4n2p1

\begin{abstract}
The thermal shrinkage of protective clothing during fire exposure plays a crucial rule in reducing the clothing protective performance. The transversal reduction in the fabric perimeter around the body due to the fabric thermal shrinkage causes a dynamic reduction in the air gap between the clothing and the body. This leads to a dynamic change in the heat transfer modes within the gap. Despite of its influential effect on the clothing performance, the thermal shrinkage of protective clothing during fire exposure has not been yet addressed in the literature. This can be attributed to the absence of a gap model that can capture the reciprocal change in heat transfer modes within the gap due to clothing shrinkage. This paper develops a finite volume model to investigate the influence of the fabric thermal shrinkage on protective clothing performance. A special attention was drawn to the model of the air gap between the clothing and skin as it responds directly to the clothing thermal shrinkage. The influence of a variation in the fabric shrinkage rate and the overall reduction in the fabric dimensions was investigated. The paper demonstrates that the clothing protective performance continuously decreases with the reduction in the fabric dimensions while the decay in the clothing protective performance is limited to small shrinkage rates of the fabric. Moreover, this decay in the clothing performance vanishes at high shrinkage rates of the fabric.
\end{abstract}

Keywords: fabric shrinkage, fire exposure, conduction-radiation, thermal radiation, finite volume method.

\section{Introduction}

Protective clothing is widely used in many industries and applications such as petroleum and petrochemical industries and municipal firefighting to seek protection from thermal and fire exposures. The thermal protective performance (TPP) of the clothing is determined by estimating heat transfer from the thermal source to the skin through clothing, which causes skin burns as a result. Standard bench top tests (ISO 9151, 1995, ASTM D 4108, 1987, ASTM F, 1999, and NFPA, 2007) are used to evaluate the TPP of fabric specimens while manikin test (ASTM F, 2000) is used to evaluate the TPP of the whole garment at different locations of the body.

Modeling the thermal performance of protective clothing has been extensively reported in the literature during the past decade. Torvi (1997) and Torvi and Dale (1999) modeled heat transfer in $\operatorname{Kevlar}^{\circledR} / \mathrm{PBI}$ and Nomex ${ }^{\circledR}$ flame-resistant fabric during a flame TPP test. Mell and Lawson (2000) modeled heat transfer in multiple layers protective garment during radiant exposure. Tan, Crown and Capjack (1998) studied the design of flightsuit protective garment for optimum protection to flight personnel. Chitrphiromsri and Kuznetsov (2005) and Song, Chitrphiromsri and Ding (2008) modeled heat and moisture transfer through firefighters' clothing in fire exposure and local flame test, respectively. Zhu and Zhang (2009) considered the fabric thermal degradation at high temperature during radiant exposure. Mercer and Sidhu $(2008,2009)$ investigated the performance of protective clothing with embedded phase change material.

The air gap between the fabric and skin plays an essential role in determining the performance of protective clothing during fire exposure. This role was acknowledged in the literature in several studies. For example, Torvi, Dale and Faulkner (1999) investigated the effect of the gap width on the protective performance of a flame-resistant fabric during a flame TPP test. Sawcyn and Torvi (2005) and Talukdar, Torvi, Simonson and Sawcyn (2010) attempted to improve the modeling of the air gap in bench top tests of protective fabrics. The 3-D body scanning technology was used (Song, Barker, Hamouda, Kuznetsov, Chitrphiromsri, \& Grimes, 2004; Kim, Lee, Li, Corner, \& Paquette, 2002; Mah \& Song, 2010a; Mah \& Song, 2010b) to determine the widths and 
distribution of air gaps between flame-resistant garment and manikin body. Ghazy and Bergstrom (2010) developed a numerical model for single layer protective clothing that considers the combined conduction-radiation heat transfer between the fabric and the skin. Then, Ghazy and Bergstrom (2011) further investigated the influence of the conduction-radiation in the gap between protective clothing and the skin on the overall performance of the clothing. Ghazy and Bergstrom (2012) also developed a model for heat transfer in multiple layers firefighters' clothing that considers the combined conduction-radiation heat transfer within the air gaps between clothing layers. Ghazy (2013) developed a novel air gap model that stands middle way between the conduction-radiation model introduced in Ghazy (2011) and the approximate air gap model exists elsewhere in the literature.

The thermal shrinkage of protective clothing in thermal or fire exposures significantly affects the clothing performance. The transversal reduction in the fabric perimeter around the body due to fabric thermal shrinkage causes a dynamic reduction in the air gap between the clothing and the body. This leads to a corresponding variation in the total heat transfer through the gap and an interchanging variation in its modes. In addition, the reduction in the gap width caused by thermal shrinkage and hence the overall protective performance of the clothing depends on the total reduction in fabric dimensions and the shrinkage rate of the fabric.

The influence of the thermal shrinkage on the performance of protective clothing during fire exposure has not been yet addressed in the literature. This is because the lack of knowledge about shrinkage rates of fire-resistant fabrics during fire exposure. In addition, the approximate analysis of the air gap that most of the models in the literature adopted is not capable of considering the dynamic variation in the air gap between the clothing and the skin due to fabric thermal shrinkage. This paper numerically investigates the effect of the fabric's thermal shrinkage during fire exposure on the overall performance of protective clothing. A special attention was drawn to modeling heat transfer through the gap since it responds directly to the fabric thermal shrinkage. The temperature dependence of the thermophysical properties of the air gap and the fabric was accounted for. The influence of a variation in the fabric shrinkage rate and the reduction in the fabric dimensions on the clothing protective performance was studied to capture different forms of fabric thermal shrinkage.

\section{Problem Description}

A typical protective clothing system is shown in Figure 1. The clothing system comprises a fire-resistant fabric that is exposed to a heat flux of about $80 \mathrm{~kW} / \mathrm{m}^{2}$ from a lab burner, the human skin that consists of epidermis, dermis and subcutaneous layers and an air gap enclosed between the fabric and the skin. The energy equations for the clothing elements are expressed as follows.

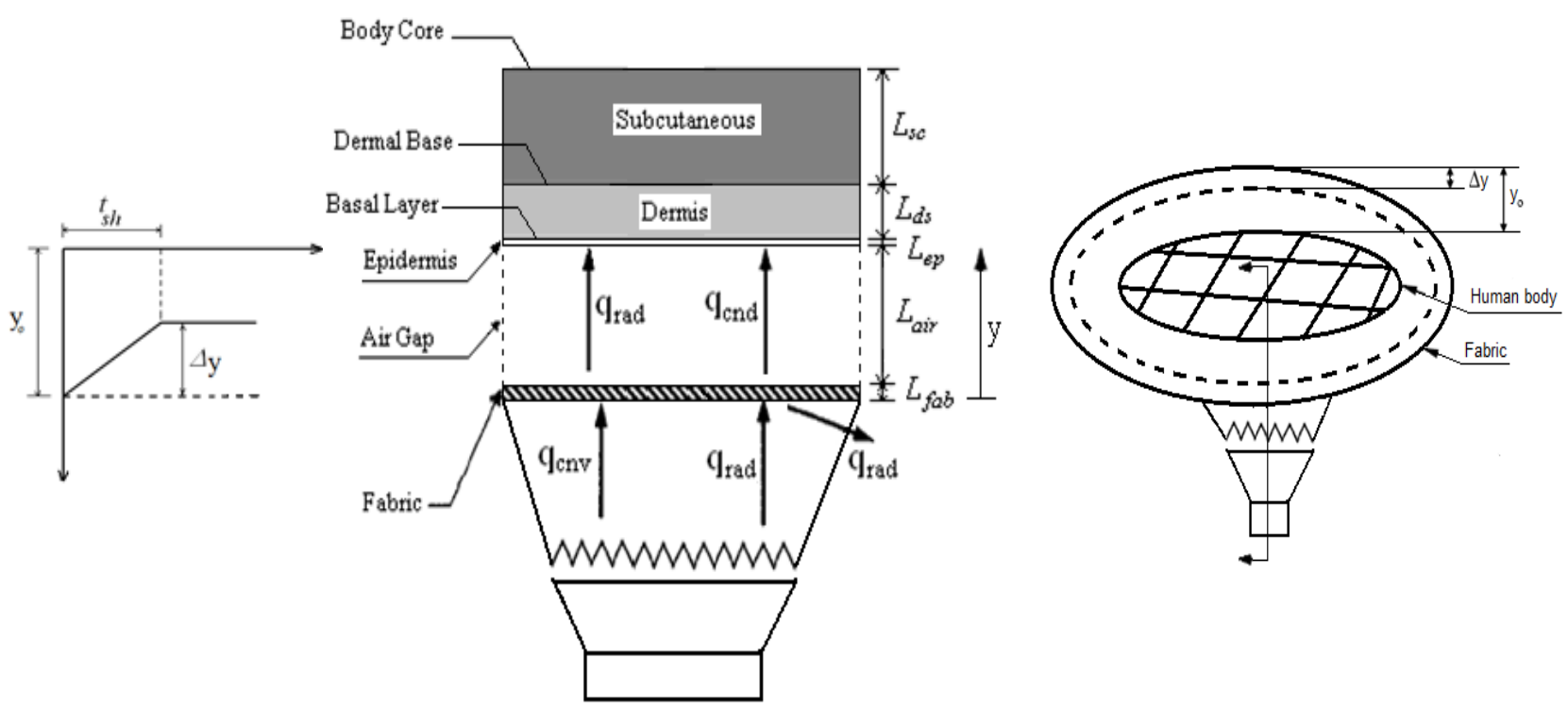

Figure 1. A schematic diagram of protective clothing

\subsection{Heat Transfer in Fire-Resistant Fabrics}

The transient energy equation for the Kevlar ${ }^{\circledR} / \mathrm{PBI}$ fabric was introduced by Torvi (1997) and Torvi and Threlfall (2006) as 


$$
\begin{array}{rrr}
\rho C^{A}(T) \frac{\partial T}{\partial t}=\frac{\partial}{\partial y}\left(k(T) \frac{\partial T}{\partial y}\right)+\gamma \sigma \varepsilon_{g} T_{g}^{4} \exp (-\not y) & 0<t \leq t_{\exp } \\
\rho c_{P}(T) \frac{\partial T}{\partial t}=\frac{\partial}{\partial y}\left(k(T) \frac{\partial T}{\partial y}\right) & t>t_{\exp }
\end{array}
$$

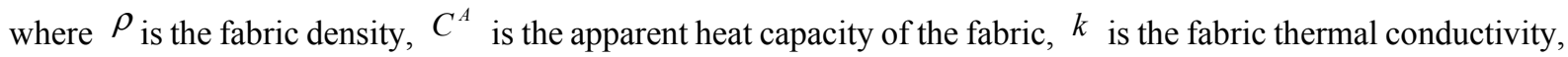
$\sigma$ is Stefan-Boltzmann constant, $T_{g}$ is hot gases temperature, $\mathcal{E}_{g}$ is hot gases emissivity, $\gamma$ is the extinction coefficient of the fabric and $t_{\exp }$ is the exposure duration.

The boundary conditions of the fabric are

$$
\begin{array}{cc}
-\left.k_{f a b}(T) \frac{\partial T_{f a b}}{\partial y}\right|_{y=0}=h_{f l}\left(T_{g}-T_{f a b(y=0)}\right)-\sigma \varepsilon_{f a b 1}\left(1-\varepsilon_{g}\right)\left(T_{f a b(y=0)}^{4}-T_{a m b}^{4}\right) & 0<t<t_{\text {exp }} \\
-\left.k_{f a b}(T) \frac{\partial T_{f a b}}{\partial y}\right|_{y=0}=h_{c n v}\left(T_{f a b(y=0)}-T_{a m b}\right)+\sigma \varepsilon_{f a b 1}\left(T_{f a b(y=0)}^{4}-T_{a m b}^{4}\right) & t>t_{\exp } \\
-\left.k_{f a b}(T) \frac{\partial T_{f a b}}{\partial y}\right|_{y=L_{f a b}}=\left.q_{y}^{\prime \prime}(\vec{r})\right|_{y=L_{f a b}}-\left.k_{a i r}(T) \frac{\partial T_{a i r}}{\partial y}\right|_{y=L_{f a b}} & t>0
\end{array}
$$

where $h_{f l}$ is the flame convection heat transfer coefficient, $h_{c n v}$ is the convection heat transfer coefficient from the clothing to the ambient surroundings, $\varepsilon_{f a b 1}$ is the emissivity of the fabric exposed surface, $T_{a m b}$ is ambient temperature and $\left.q_{y}^{\prime \prime}(\vec{r})\right|_{y=L_{f a b}}$ is the emitted radiation from the fabric backside surface, which is discussed in section 2.2 .

The initial condition of the fabric is

$$
T_{f a b}(y, t=0)=T_{a m b}
$$

\subsection{Heat Transfer in the Air Gap}

The transient heat transfer in the gap is written as

$$
\rho(T) c_{P}(T) \frac{\partial T}{\partial t}=\frac{\partial}{\partial y}\left(k(T) \frac{\partial T}{\partial y}\right)-\frac{\partial q_{R}^{\prime \prime}}{\partial y}
$$

where $\rho, c_{P}$, and $k$ are the density, specific heat, and thermal conductivity of the air gap, respectively and $\frac{\partial q_{R}^{\prime \prime}}{\partial y}$ is the divergence of the radiative heat flux through the air gap. Note that for gap widths of $1 / 4 \mathrm{in}$. (6.4 mm) or less, the computed Rayleigh number within the gap is less than the critical Rayleigh number for nature convection heat transfer. That makes radiation and conduction are the dominant modes of heat transfer within the gap.

The width of the gap between the fabric and the skin due to fabric shrinkage is

$$
\begin{array}{ll}
y=y_{o}-\left(\frac{\Delta y}{t_{s h k}} \times t\right) & t<t_{s h k} \\
y=y_{o}-\Delta y & t>t_{s h k}
\end{array}
$$

where $y$ is the air gap width at any time $t, y_{o}$ is the nominal air gap width, $\Delta y$ is the reduction in the gap width due to the fabric thermal shrinkage and $t_{\text {shk }}$ is the time over which the fabric thermal shrinkage takes place, as shown in Figure 1.

The Radiative Transfer Equation (RTE) of the air gap (Modest, 2003) is written as 


$$
\frac{d I(\vec{r}, \hat{s})}{d s}=-\kappa(\vec{r}) I(\vec{r}, \hat{s})+\kappa(\vec{r}) I_{b}(\vec{r})
$$

where $I$ is the radiation intensity, $s$ is the geometric distance, $\vec{r}$ is the spatial position, $\hat{s}$ is the angular direction and $\kappa$ is the gap absorption coefficient.

The unit direction $\hat{s}$ is defined in y-direction as

$$
\hat{s}=(\sin \theta \sin \phi) \hat{e}_{y}
$$

where $\theta$ is polar angle, $\phi$ is azimuthal angle and $\hat{e}_{y}$ is unit vector in y-direction.

The black body intensity, $I_{b}$, is defined as

$$
I_{b}=\frac{\sigma T^{4}}{\pi}
$$

where $T$ is the medium absolute temperature and $\sigma$ is the Stephan-Boltzmann constant.

The boundary conditions for the RTE of the air gap (Equation 8) are written as

$$
\begin{array}{lr}
I_{f a b}(\vec{r}, \hat{s})=\varepsilon_{f a b 2}(\vec{r}) I_{b, f a b}(\vec{r})+\frac{\rho_{f a b 2}(\vec{r})}{\pi} \int_{\hat{s}^{\prime} \hat{n}<0} I(\vec{r}, \hat{s})\left|\hat{s}^{\prime} \cdot \hat{n}\right| d \Omega^{\prime} & \text { at } y=L_{f a b} \\
I_{e p}(\vec{r}, \hat{s})=\varepsilon_{e p}(\vec{r}) I_{b, e p}(\vec{r})+\frac{\rho_{e p}(\vec{r})}{\pi} \int_{\hat{s}^{\prime} \cdot \hat{n}<0} I(\vec{r}, \hat{s})\left|\hat{s}^{\prime} \cdot \hat{n}\right| d \Omega^{\prime} & \text { at } \quad y=L_{f a b}+L_{a i r}
\end{array}
$$

where $\varepsilon_{f a b 2}$ and $\rho_{f a b 2}$ are the emissivity and reflectivity of the fabric backside, $\varepsilon_{e p}$ and $\rho_{e p}$ are the emissivity and reflectivity of the epidermis surface, $\hat{s}^{\prime}$ is reflected ray unit direction, $\hat{n}$ is unit normal to the surface and $d \Omega^{\prime}$ is solid angle containing the reflected ray.

The divergence of radiative heat flux in the air gap energy equation (Equation 5) is calculated as

$$
\frac{\partial q_{R}^{\prime \prime}}{\partial y}=\kappa\left(4 \pi I_{b}(\vec{r})-G(\vec{r})\right)
$$

where the incident radiation, $G(\vec{r})$, is defined as

$$
G(\vec{r})=\int_{4 \pi} I(\vec{r}, \hat{s}) d \Omega
$$

The radiation heat flux emitted from the fabric and that is incident on the skin surface are calculated as

$$
\begin{gathered}
\left.q_{y}^{\prime \prime}(\vec{r})\right|_{y=L_{f a b}}=\left.\int_{4 \pi} I(\vec{r}, \hat{s})\left(\hat{s} \cdot \hat{e}_{y}\right) d \Omega\right|_{y=L_{f a b}} \\
\left.q_{y}^{\prime \prime}(\vec{r})\right|_{y=L_{\text {fab }}+L_{\text {air }}}=\left.\int_{4 \pi} I(\vec{r}, \hat{s})\left(\hat{s} \cdot \hat{e}_{y}\right) d \Omega\right|_{y=L_{\text {fab }}+L_{\text {air }}}
\end{gathered}
$$

The RTE (Equation 8) is solved along with its boundary conditions using the Finite Volume Method (Chai \& Patankar, 2000) where the facial intensity was related to the nodal one as follows.

$$
a_{P}^{l} I_{P}^{l}=a_{N}^{l} I_{N}^{l}+a_{S}^{l} I_{S}^{l}+b^{l}
$$

where

$$
\begin{array}{r}
a_{N}^{l}=\max \left(-A_{n} D_{c n}^{l}, 0\right), \quad a_{S}^{l}=\max \left(-A_{s} D_{c s}^{l}, 0\right) \\
a_{P}^{l}=\max \left(A_{n} D_{c n}^{l}, 0\right)+\max \left(A_{s} D_{c s}^{l}, 0\right)+\kappa_{P} \Delta V_{P} \Delta \Omega^{l} \\
b^{l}=S_{P}^{l} \Delta V_{P} \Delta \Omega^{l} \\
D_{c n}^{l}=\int_{\Delta \Omega^{l}}\left(\hat{s}^{l} \cdot \hat{e}_{y}\right) d \Omega, D_{c s}^{l}=-D_{c n}^{l} \\
\Delta \Omega^{l}=\int_{\Delta \Omega^{l}} d \Omega
\end{array}
$$




$$
S_{P}^{l}=\kappa_{P} I_{b, P}
$$

The boundary conditions for the air gap energy equation (Equation 5) are as follows.

$$
\begin{aligned}
\left.T_{a i r}\right|_{y=L_{f a b}}=\left.T_{f a b}\right|_{y=L_{f a b}} & t>0 \\
\left.T_{a i r}\right|_{y=L_{f a b}+L_{a i r}}=\left.T_{e p}\right|_{y=L_{f a b}+L_{a i r}} & t>0
\end{aligned}
$$

where $T_{e p}$ is the epidermis surface temperature and $L_{a i r}$ is the air gap width.

The initial condition of the air gap is

$$
T_{\text {air }}(y, t=0)=T_{\text {amb }}
$$

\subsection{Heat Transfer in the Human Skin}

Heat transfer in the human skin is modeled by the bioheat transfer equation developed by Pennes (1948). The energy equations for the epidermis, dermis and subcutaneous layers of the skin are written as

$$
\begin{gathered}
\left(\rho c_{P}\right)_{e p} \frac{\partial T}{\partial t}=\frac{\partial}{\partial y}\left(k_{e p} \frac{\partial T}{\partial y}\right) \\
\left(\rho c_{P}\right)_{d s} \frac{\partial T}{\partial t}=\frac{\partial}{\partial y}\left(k_{d s} \frac{\partial T}{\partial y}\right)+\left(\rho c_{P}\right)_{b} \omega_{b}\left(T_{c r}-T\right) \\
\left(\rho c_{P}\right)_{s c} \frac{\partial T}{\partial t}=\frac{\partial}{\partial y}\left(k_{s c} \frac{\partial T}{\partial y}\right)+\left(\rho c_{P}\right)_{b} \omega_{b}\left(T_{c r}-T\right)
\end{gathered}
$$

where $\omega_{b}$ is the blood perfusion rate, $T_{c r}$ is the core body temperature.

The boundary conditions of the skin are

$$
\begin{array}{cc}
-\left.k_{e p}(T) \frac{\partial T_{e p}}{\partial y}\right|_{y=L_{f b b}+L_{a i r}}=\left.q_{y}^{\prime \prime}(\vec{r})\right|_{y=L_{f a b}+L_{a i r}}-\left.k_{a i r}(T) \frac{\partial T_{a i r}}{\partial y}\right|_{y=L_{j a b}+L_{a i r}} t>0 \\
\left.T_{s c}\right|_{y=L_{f a b}+L_{a i r}+L_{e p}+L_{d s}+L_{s c}}=T_{c r} \quad t>0
\end{array}
$$

where $\left.q_{y}^{\prime \prime}(\vec{r})\right|_{y=L_{f a b}+L_{a i r}}$ is the incident radiation heat flux on the skin (Equation 16) and $L_{e p}, L_{d s}$ and $L_{s c}$ are the thicknesses of the epidermis, dermis, and subcutaneous layers, respectively.

The initial conditions of the skin are represented by a linear temperature distribution from the epidermis surface $\left(32.5^{\circ} \mathrm{C}\right)$ to the subcutaneous base $\left(37^{\circ} \mathrm{C}\right)$. Skin burn injury takes place when the basal layer (the base of the epidermis layer) temperature reaches $44^{\circ} \mathrm{C}$. Henriques' integral (Henriques \& Moritz, 1947) is employed to predict times for the skin to receive burn injuries as follows.

$$
\varphi=\int_{0}^{t} P \exp \left(-\frac{\Delta E}{R T}\right) d t
$$

where the values for the activation energy $\Delta E$ of the skin and the pre-exponential factor $P$ were determined by Weaver and Stoll (1996) for second-degree burns and by Takata, Rouse and Stanley (1973) for third-degree burns. The basal layer temperature is employed in the aforementioned integral to predict times to first- and seconddegree burns. First- and second-degree burns take place when $\varphi$ reaches 0.53 and 1, respectively. Whilst the dermal base (the base of the dermis layer) temperature is employed in the integral to estimate times to third-degree burns, which occur when $\varphi$ reaches 1 .

\section{Numerical Solution}

The fabric, air gap and the skin (epidermis, dermis, and subcutaneous) energy equations were solved along with their boundary conditions using the finite volume method (Patankar, 1980) using the Gauss-Seidel point-by-point iterative scheme. The solution proceeds as follows. Within each time step, temperatures calculated in the previous time step are used as initial guess for the iteration loop. The air gap width is updated according to Equations 6 and 7. A uniform reduction in the air gap control volumes sizes is assumed whereas the air properties in each control volume do not change. Within the iteration loop, temperatures of the air gap, fabric backside and epidermis surface 
are used to solve the RTE of the gap. Next, the radiation heat flux at the boundaries of the gap and the divergence of radiative heat flux are estimated to be used in the boundary conditions of the fabric and the skin and in the energy equation of the gap. The source terms and properties of the fabric and air gap are updated in accordance with the most recent temperatures within the loop. Then, new temperatures are calculated by solving the discrete equations from the fabric exposed surface to the subcutaneous base. When temperature convergence is reached for a time step, temperatures of the basal layer and dermal base are used in Henriques' integral (Equation 32) to predict times to skin burns.

\section{Results and Discussion}

Simulations were carried out for an exposure period of 10 seconds followed by a cool down period. The parameters used in the simulation are listed in Table 1 whilst the thermophysical properties of the human skin are listed in Table 2. The dynamic reduction in the gap width between the fabric and the skin was introduced by the percentage reduction in the gap width and the rate at which this reduction takes place. These two parameters are representatives for the percentage reduction in the fabric perimeter around the body due to fabric shrinkage and the shrinkage rate of the fabric, respectively.

Table 1. Simulation parameters

\begin{tabular}{lll}
\hline \multicolumn{2}{l}{ Property } & Value \\
\hline$\rho_{f a b}$ & Fabric density & $323 \mathrm{~kg} / \mathrm{m}^{3}$ \\
$\gamma_{f a b}$ & Fabric extinction factor & 0.01 \\
$\mathcal{E}_{f a b}$ & Fabric emissivity & 0.9 \\
$\tau_{f a b}$ & Fabric transmissivity & 0.01 \\
$L_{f a b}$ & Fabric thickness & $0.6 \mathrm{~mm}$ \\
$T_{g}$ & Hot gases temperature & $2000 \mathrm{~K}$ \\
$\varepsilon_{g}$ & Hot gases emissivity & 0.02 \\
$h_{f l}$ & Flame convective heat transfer coefficient & $40 \mathrm{~W} / \mathrm{m}^{2} \mathrm{~K}$ \\
\hline
\end{tabular}

Table 2. Thermophysical properties of the human skin

\begin{tabular}{lllll}
\hline Property & Epidermis & Dermis & Subcutaneous & Blood \\
\hline Density $\left(\mathrm{Kg} / \mathrm{m}^{3}\right)$ & 1200 & 1200 & 1000 & 1060 \\
Specific Heat $\left(\mathrm{J} / \mathrm{Kg}^{\circ} \mathrm{C}\right)$ & 3598 & 3222 & 2760 & 3770 \\
Thermal Conductivity $\left(\mathrm{W} / \mathrm{m}^{\circ} \mathrm{C}\right)$ & 0.255 & 0.523 & 0.167 & - \\
Thickness $(\mathrm{m})$ & $8 \times 10^{-5}$ & $2 \times 10^{-3}$ & $1 \times 10^{-2}$ & - \\
Blood Perfusion Rate $\left(\mathrm{m}^{3} / \mathrm{s}\right) / \mathrm{m}^{3}$ tissue & - & - & - & $1.25 \times 10^{-3}$ \\
\hline
\end{tabular}

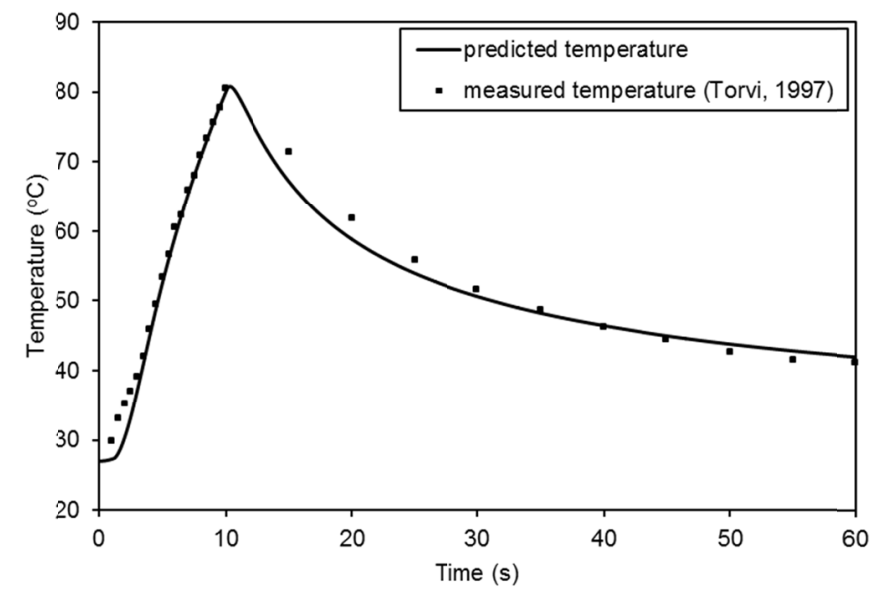

Figure 2. Comparison between measured and predicted temperatures of the skin simulant surface 
The model validation has been done by simulating the open flame bench top test performed by Torvi (1997) using skin simulant gauge and a constant air gap width of $6.4 \mathrm{~mm}(1 / 4 \mathrm{in}$.). A comparison between the predicted and measured temperatures of the skin simulant surface during the exposure and cool down periods are held in Figure 2. The model successfully predicted the skin simulant surface temperature during both the exposure and cool down periods. The small deviation between the prediction and measurements can be attributed to other factors that are not considered in the model such as the fabric thermal pyrolysis. However, identifying the source of the small discrepancy noted in Figure 2 may require extensive experimental data.

The effect of a variation in the percentage reduction in the gap width on heat transfer within the gap from the fabric to the skin is compared to the case of no fabric shrinkage and illustrated by Figure 3. The conduction heat flux through the air gap increases as the percentage reduction increases, Figure 3(a), while the radiation heat flux decreases with the increase in the percentage reduction, Figure 3(b). Nevertheless, the variation in the conduction heat flux with a variation in the percentage reduction is bigger than that in the radiation heat flux. In addition, the divergence in the conduction heat flux with a variation in the percentage reduction starts earlier than that of the radiation heat flux. Moreover, the divergence in the radiation heat flux drops quickly during the cool down period compared to the conduction heat flux. In addition, the divergence in the conduction and radiation heat fluxes within the gap is not linearly proportional to the variation in the percentage reduction. For example, the divergence in the energy transfer (conduction and/or radiation) within the gap due to a variation in the percentage reduction from $10 \%$ to $30 \%$ is less than that due to a variation from $30 \%$ to $50 \%$. Furthermore, the remarkable deviation in the conduction and radiation heat fluxes within the gap from the case of no fabric shrinkage proves the influential effect of the fabric thermal shrinkage on the heat transfer to the skin and hence on the clothing protective performance.

(a)
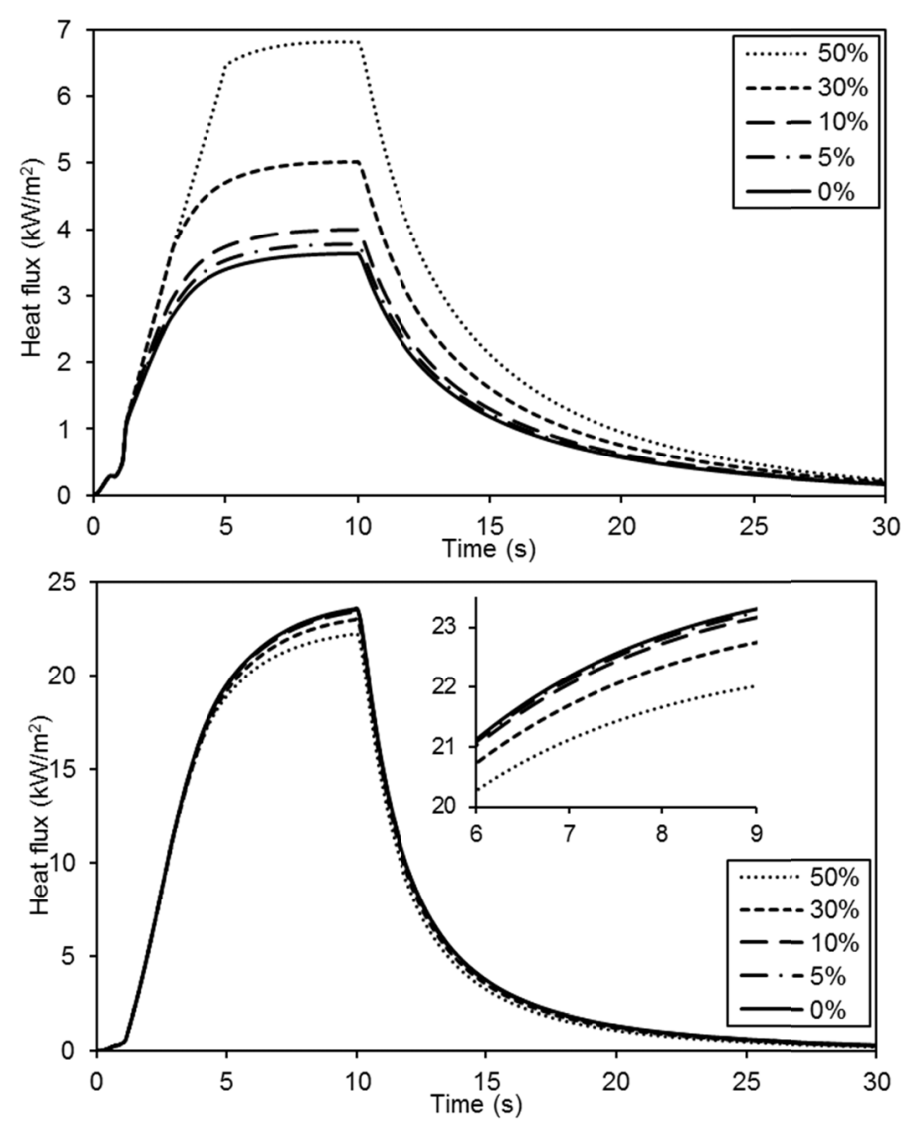

Figure 3. Effect of a reduction in the gap width on heat transfer through the gap: (a) conduction heat flux from the fabric, (b) emitted radiation from the fabric 
(a)
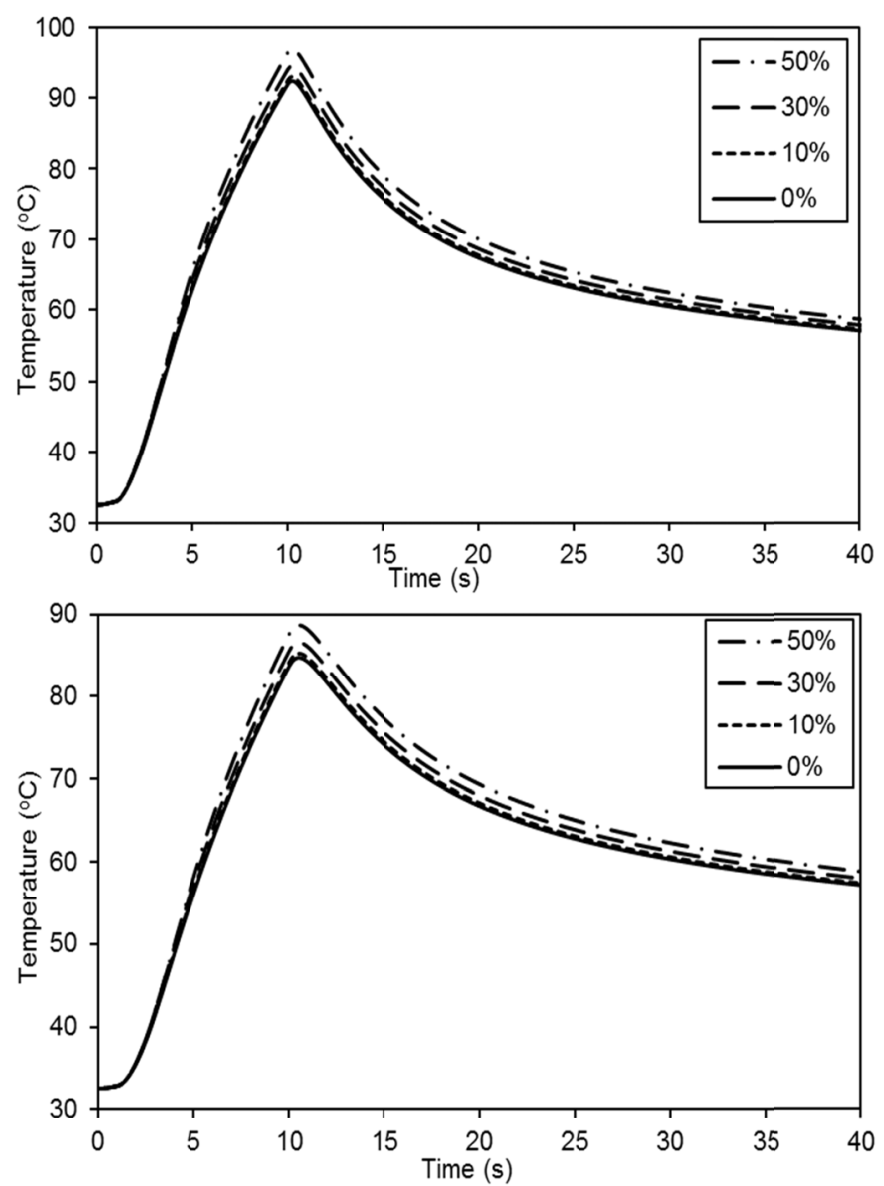

(b)

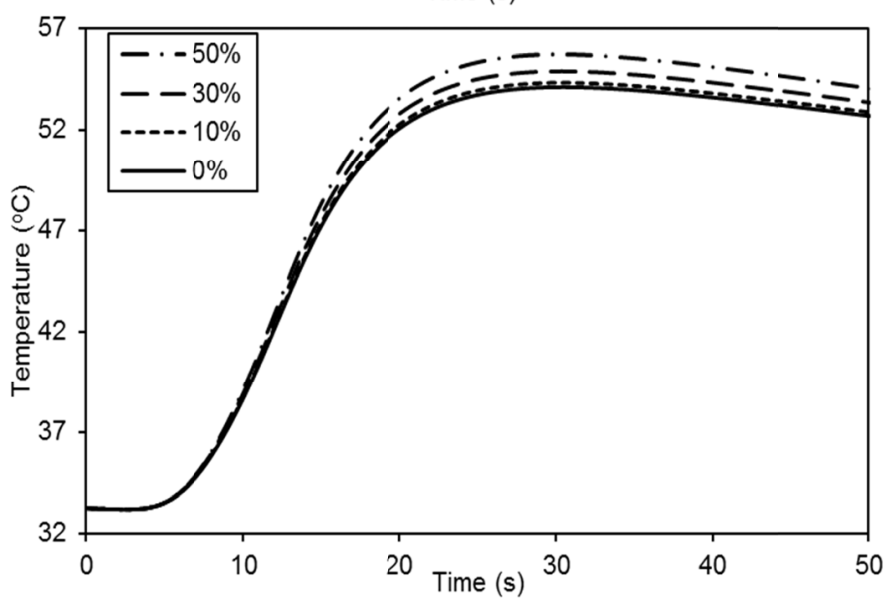

Figure 4. Effect of a reduction in the air gap width on the temperature distribution within the skin: (a) epidermis surface, (b) basal layer, (c) dermal base

The influence of a variation in the percentage reduction in the gap width on the temperature distributions within the skin is shown in Figure 4. The temperatures of the epidermis surface (Figure 4a), basal layer (Figure 4b) and dermal base (Figure 4c) increase with the increase in the percentage reduction. However, the increase in the skin layers temperatures is not linearly proportional to the increase in the percentage reduction. Moreover, the closer the fabric to the skin due to the shrinkage, the higher the influence of the variation in the percentage reduction on the temperature distributions within the skin. In addition, the divergences in the temperatures of the epidermis surface and the basal layer become evident by the end of the exposure period while the divergence in the dermal base temperature develops during the cool down period. Nevertheless, the divergence in the temperatures of the skin layers last during the cool down period. 
The influence of a variation in the reduction in the gap width due to fabric shrinkage on times to skin burn injuries is shown in Figure 5. Times to first- and second-degree burns, shown in Figure 5a, decrease almost linearly with the increase in the percentage reduction from $0 \%$ (no shrinkage) to $50 \%$. Any reduction in the air gap width beyond $50 \%$ does not affect times to first- and second-degree burns. On the other hand, times to third-degree burns, shown in Figure 5b, continuously decrease with the increase in the percentage reduction.

(a)

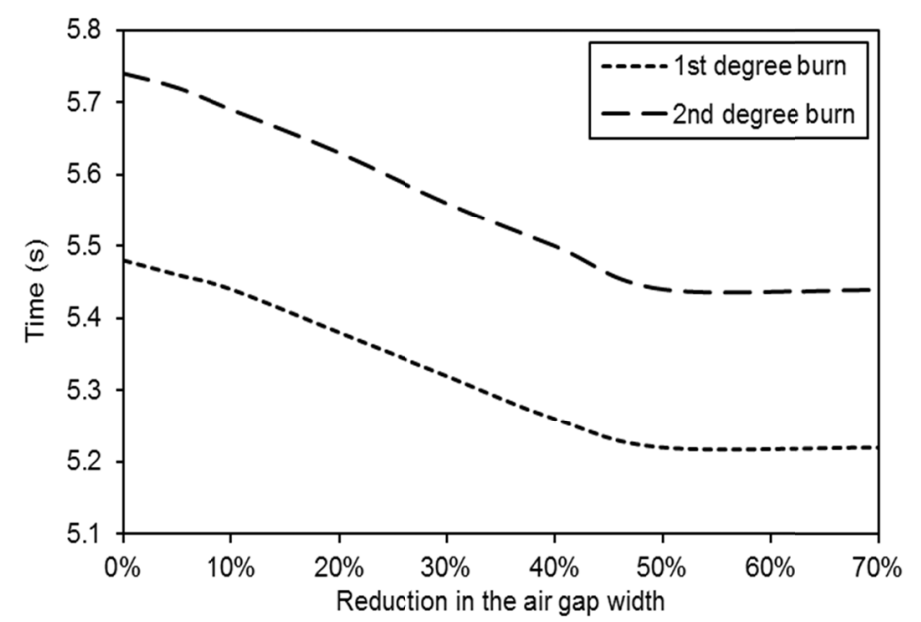

(b)

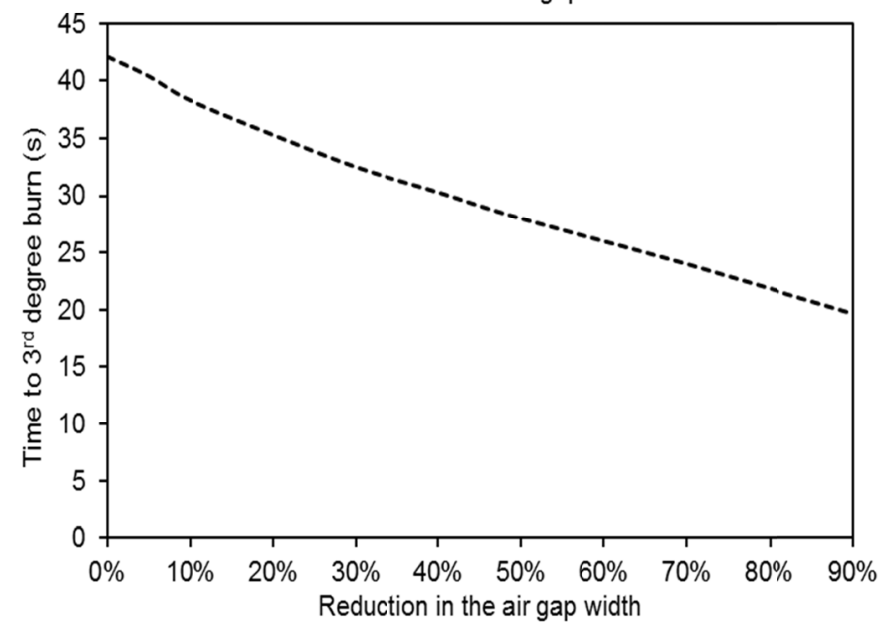

Figure 5. Effect of the reduction in the air gap width on skin burn predictions: (a) first- and second-degree burns, (b) third-degree burns

Figure 6 illustrates the effect of a variation in the reduction rate (fabric shrinkage rate) on the energy transfer within the gap. As shown in Figure 6a, any deviation in the reduction rate from the case of $0 \% / \mathrm{s}$ (no shrinkage) causes a notable increase in the conduction heat flux within the gap. In addition, although the conduction heat flux increases as the reduction rate increases, the divergence in the conduction heat flux decreases with the increase in the reduction rate. This divergence drops off by the end of the exposure period and the deviation in the conduction heat flux from the case of no shrinkage vanishes gradually during the cool down period. On the other hand, the radiation heat flux within the gap decreases with the increase in the reduction rate, as shown in Figure 6b. However, like the distribution of conduction heat flux, the divergence in the radiation heat flux decreases with the increase in the reduction rate. Nevertheless, the divergence in the radiation heat flux with a variation in the reduction rate is less than that of the conduction heat flux. 
(a)
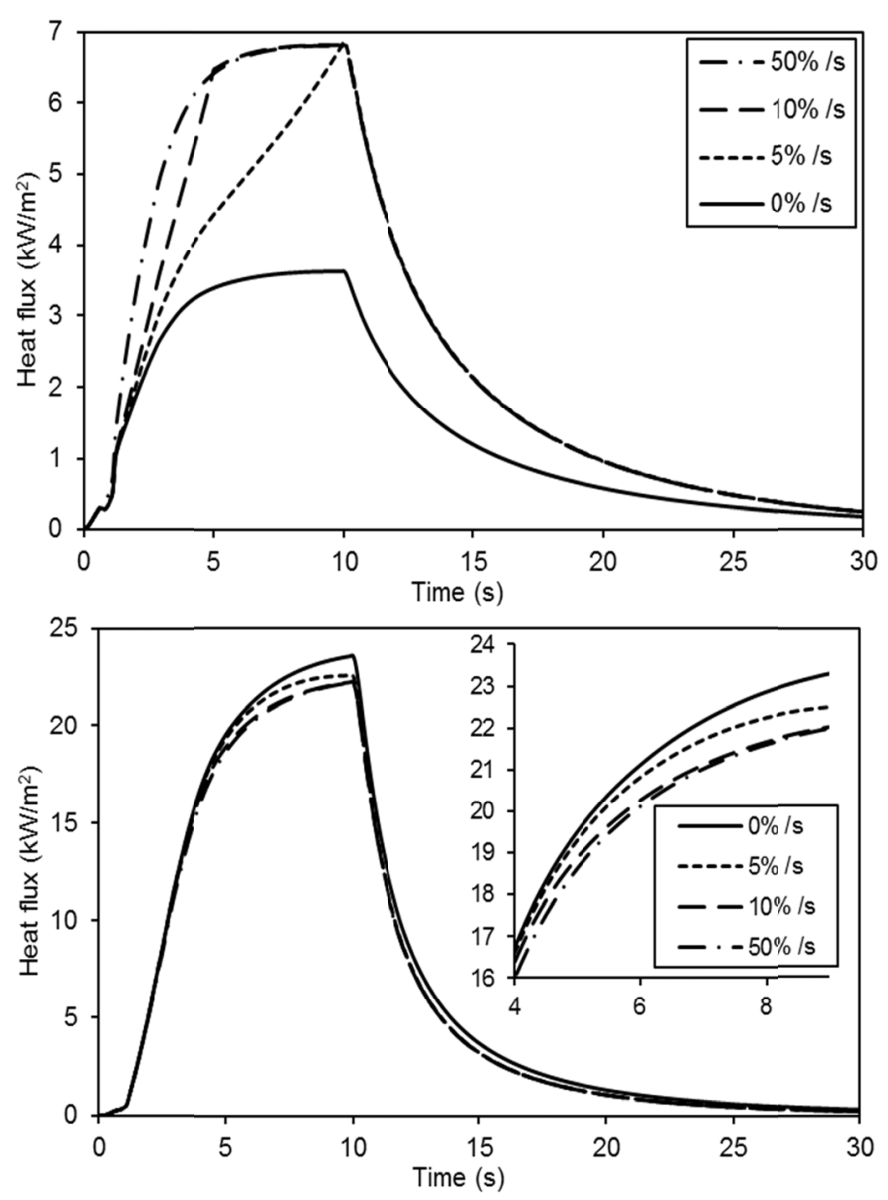

Figure 6. Effect of the reduction rate in the air gap width on energy transfer through the gap: (a) conduction heat flux at the fabric air interface, (b) emitted radiation from the fabric backside

The variation in the temperature distributions within the skin is illustrated in Figure 7. Expectedly, skin layers temperatures increase as the reduction rate increases. Nevertheless, the divergence in the skin layers temperatures decreases as the reduction rate increases; a rapid reduction in the air gap width does not make a big difference in the temperature distributions within the skin as compared to a slow one. For example, the increase in the skin layers temperatures due to a variation in the reduction rate from $5 \% / \mathrm{s}$ to $50 \% / \mathrm{s}$ is minimal compared to that caused by a variation from $0 \% / \mathrm{s}$ (no shrinkage) to $5 \% / \mathrm{s}$. However, the divergence in the skin temperatures from the case of no shrinkage lasts during the cool down period. 
(a)

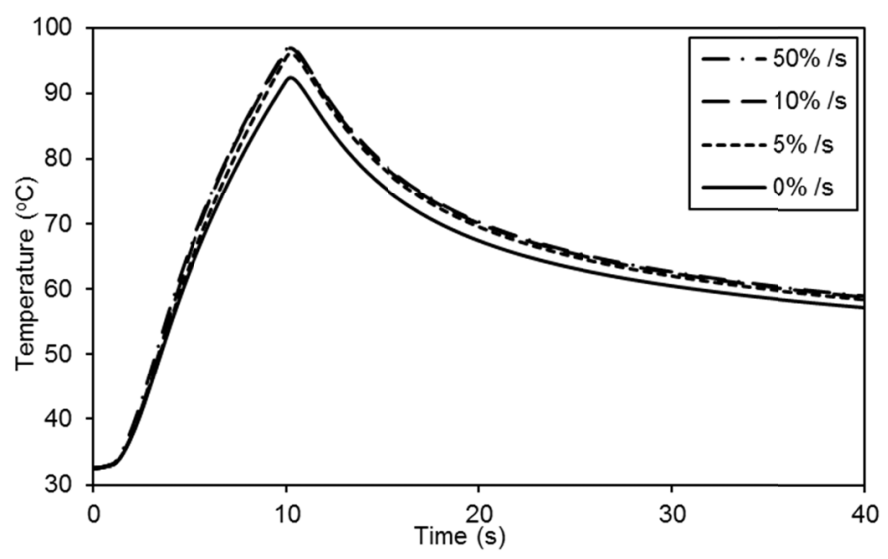

(b)

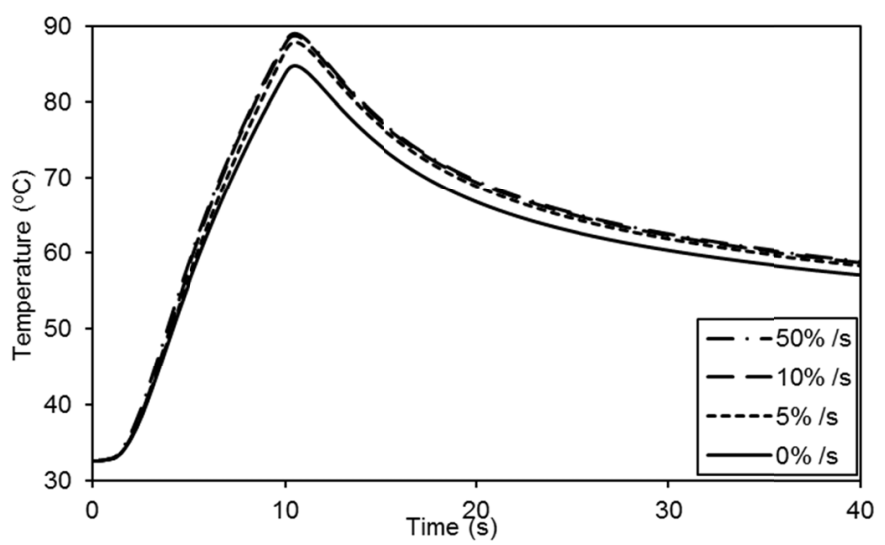

(c)

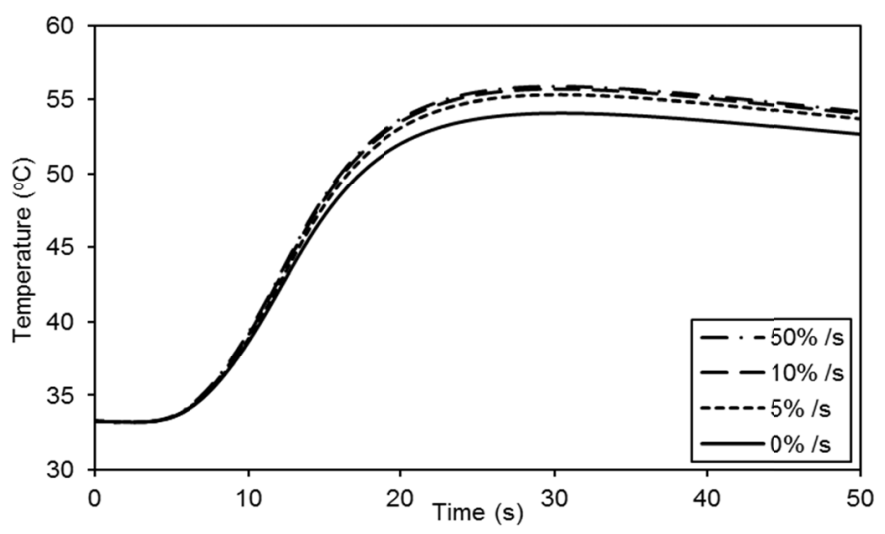

Figure 7. Effect of the reduction rate in the air gap width on the temperature distribution within the skin: (a) epidermis surface, (b) basal layer, (c) dermal base

The influence of a variation in the reduction rate on skin burn predictions is illustrated by Figure 8 . Times to firstand second-degree burns, shown in Figure 8a, decrease with the increase in the reduction rate from $0 \% / \mathrm{s}$ to $20 \% / \mathrm{s}$. There is almost no change in times to first-and second-degree burns for reduction rates that are greater than $20 \% / \mathrm{s}$. Times to third-degree burns, shown in Figure $8 \mathrm{~b}$, drop sharply as the reduction rate increases from $0 \% / \mathrm{s}$ to $10 \% / \mathrm{s}$. However, for reduction rates that are greater than $20 \% / \mathrm{s}$, times to third-degree burns tend to be almost constant. 
(a)

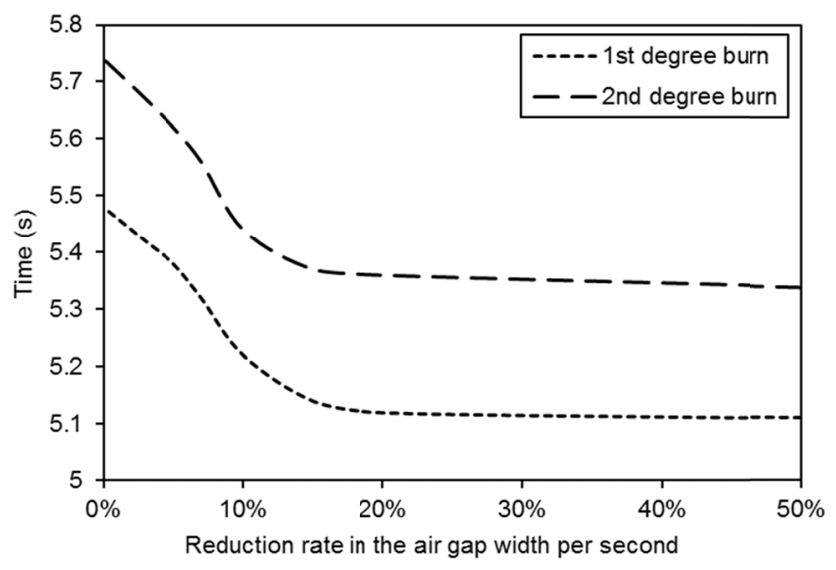

(b)

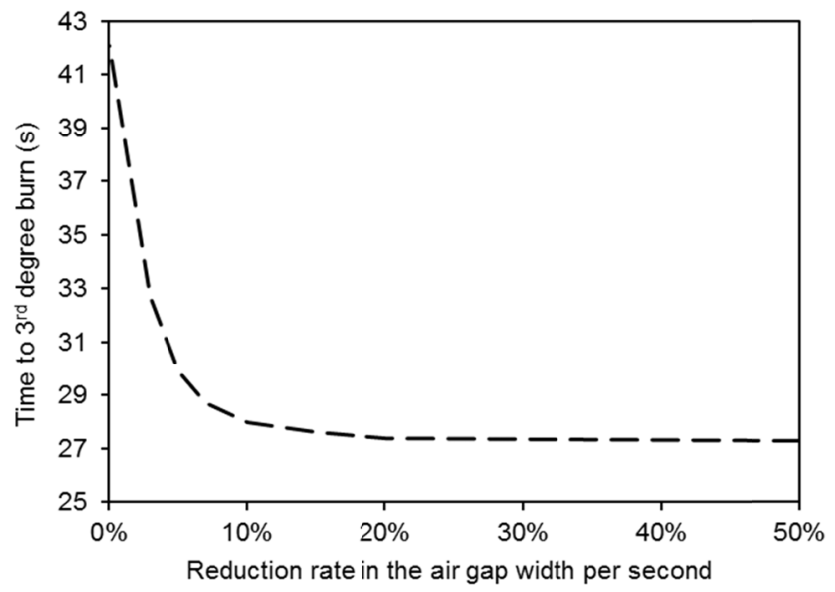

Figure 8. Effect of the reduction rate in the air gap width on skin burn predictions: (a) first-and second-degree burns, (b) third-degree burns

Figure 9 illustrates the influence of a variation in the reduction rate on skin burn predictions for different reduction percentages in the gap width. Similar to the trends shown in Figure 8, times to first (Figure 9a), second (Figure 9b) and third (Figure 9c) degree burns decrease with the increase in the reduction rate for low reduction rates then they become almost constant for higher reduction rates. The reduction rates at which times to skin burns become steady increase as the percentage reduction increases. In other words, the influence of the reduction rate on times to skin burn injuries increases with the increase in the percentage reduction in the air gap width. Lastly, Figure 9 shows the ultimate reduction in the gap width due to the fabric thermal shrinkage is more influential in determining the protective performance of the clothing than the rate at which this reduction takes place.

\section{Conclusions}

A finite volume model was developed to investigate the effect of the fabric thermal shrinkage on the performance of protective clothing during fire exposure. The model carefully accounted for the changes in the air gap between the fabric and the skin during the fabric thermal shrinkage. The influences of the reduction in the clothing perimeter around the body and the shrinkage rate of the fabric were numerically investigated. The following conclusions can be drawn from the study.

1) The protection provided by the clothing is considerably reduced by the thermal shrinkage of the fabric during fire exposure, particularly by the reduction in the clothing perimeter and the shrinkage rate of the fabric. Both parameters unequally affect the heat transfer from the fabric to the skin and hence the clothing protective performance.

2) A variation in the clothing perimeter or the fabric shrinkage rate nonlinearly alters the conduction and radiation heat fluxes from the clothing to the skin. However, the variation in the conduction heat flux from the fabric to the skin is bigger than that in the radiation heat flux.

3) The clothing protective performance linearly decreases with the reduction in the clothing perimeter around the body while its reduction with the increase in the fabric shrinkage rate is limited to small shrinkage rates. 
4) The reduction in the clothing perimeter is more influential on the clothing protective performance than the shrinkage rate of the fabric. The closer the clothing is to the skin due to the fabric thermal shrinkage, the less the protective performance of the clothing.

5) The reduction in the clothing protective performance caused by an increase in the shrinkage rate of the fabric is worsened by the reduction of the clothing perimeter.

Finally, the paper, in all events, demonstrates the influential role that the air gap between protective clothing and the skin plays in determining the clothing performance during fire exposure. Furthermore, the paper, in general context, contributes to the knowledge of the combined conduction-radiation heat transfer in enclosures with dynamically changing widths filled with a radiation participating medium and bounded with high temperature and heat flux conditions.

(a)
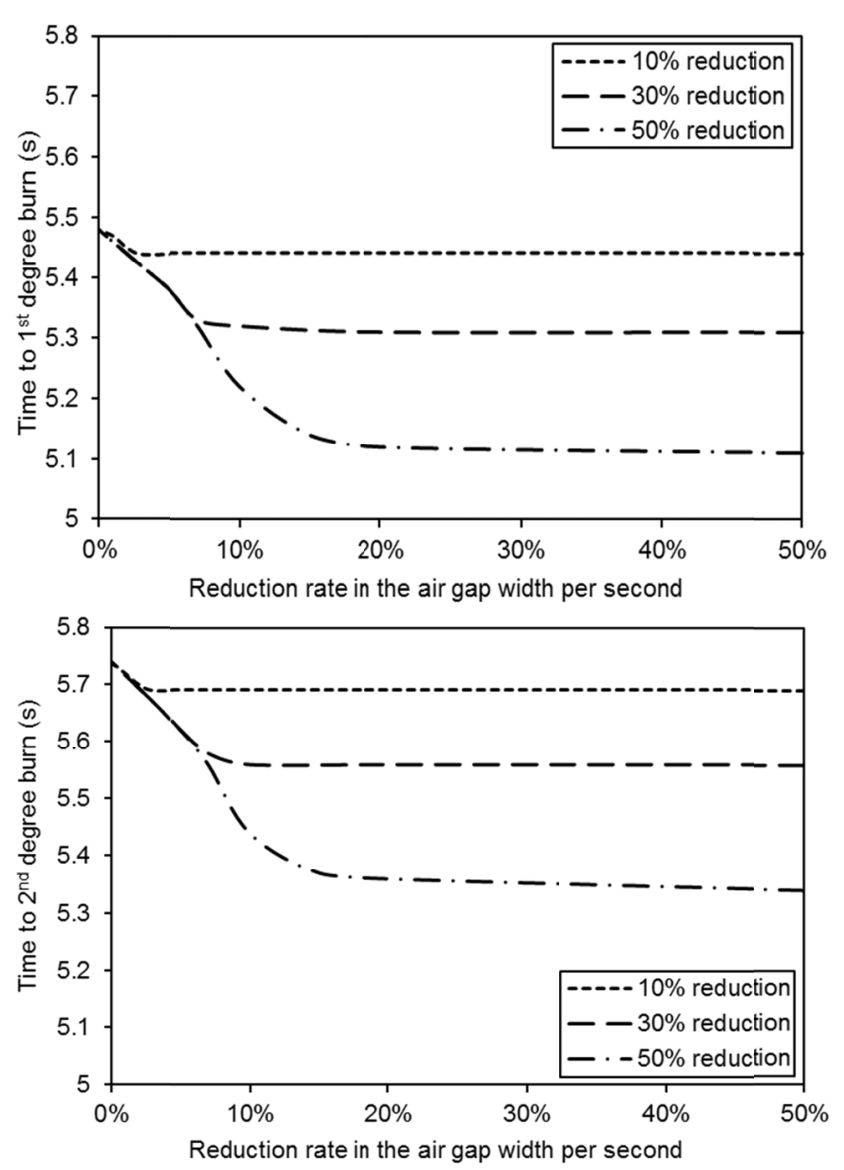

(c)

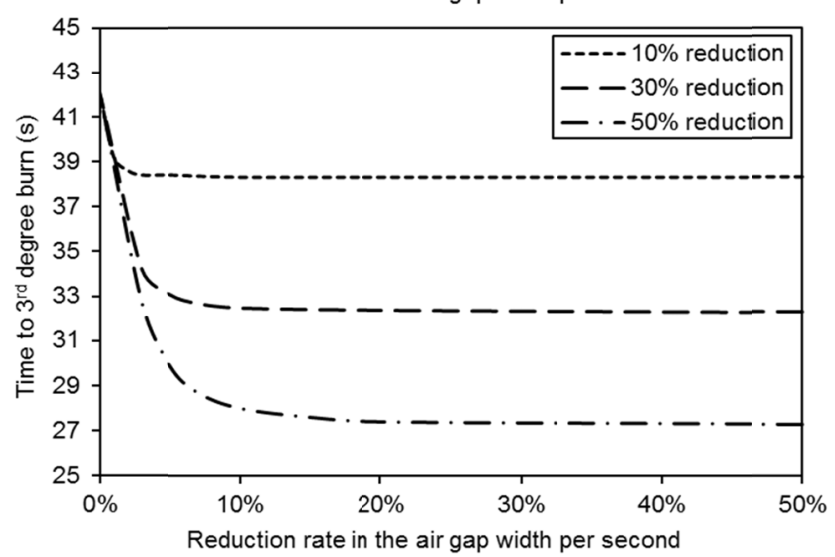

Figure 9. Skin burn predictions for different reduction rates and reduction percentages in the gap width: (a) firstdegree burns, (b) second-degree burns, (c) third-degree burns 


\section{References}

American Society for Testing Materials. (1987). ASTM D 4108 Standard Test Method for Thermal Protective Performance of Materials and Clothing by open-Flame Method. West Conshohocken, Pennsylvania.

American Society for Testing Materials. (1999). ASTM F 1939 a Standard Test Method for Radiant Protective Performance of Flame Resistant Clothing Materials. West Conshohocken, Pennsylvania.

American Society for Testing Materials. (2000). ASTM F 1930 Standard Test Method for Evaluation of Flame Resistant Clothing for Protection Against Flash Fire Simulations Using an Instrumented Thermal Manikin. West Conshohocken, Pennsylvania.

Chai, J. C., \& Patankar, S. V. (2000). Finite-Volume Method for Radiation Heat Transfer. In J. P. Hartnett, \& T. F. Ivrine (Ed.), Advances in Numerical Heat Transfer (Vol. 2, pp. 109-141). New York: Academic Press.

Chitrphiromsri, P., \& Kuznetsov, A. V. (2005). Modeling Heat and Moisture Transport in Firefighter Protective Clothing during Flash Fire Exposure. Heat and Mass Transfer, 41, 206-215. http://dx.doi.org/10.1007/s00231-004-0504-x

Ghazy, A. (2011). Air Gaps in Protective Clothing during Flash Fire Exposure (Doctoral dissertation). University of Saskatchewan, Saskatoon, Saskatchewan.

Ghazy, A. (2013). Numerical Study of the Air Gap between Fire-Protective Clothing and the Skin. Industrial Textiles. http://dx.doi.org/ 10.1177/1528083713483784

Ghazy, A., \& Bergstrom, D. J. (2010). Numerical Simulation of Transient Heat Transfer in a Protective Clothing System during a Flash Fire Exposure. Numerical Heat Transfer A, 58, 702-724. http://dx.doi.org/10.1080/10407782.2010.516691

Ghazy, A., \& Bergstrom, D. J. (2011). Influence of the Air Gap between Protective Clothing and Skin on clothing Performance during Flash Fire Exposure. Heat Mass Transfer, 47, 1275-1288. http://dx.doi.org/10.1007/s00231-011-0791-y

Ghazy, A., \& Bergstrom, D. J. (2012). Numerical Simulation of Heat Transfer in Firefighters' Protective Clothing with Multiple Air Gaps during Flash Fire Exposure. Numerical Heat Transfer A, 61, 569-593. http://dx.doi.org/10.1080/10407782.2012.666932

Henriques, F. C., Jr., \& Moritz, A. R. (1947). Studies of thermal injuries I: The conduction of heat to and through skin and the temperatures attained therein. A theoretical and experimental investigation. American Journal of Pathology, 23, 531-549.

International Organization for Standardization. (1995). ISO 9151 Protective Clothing against Heat and Flame Determination of Heat Transmission on Exposure to Flame. Geneva, Switzerland.

Kim, I. Y., Lee, C., Li, P., Corner, B. D., \& Paquette, S. (2002). Investigation of Air Gaps Entrapped in Protective Clothing Systems. Fire and Materials, 26, 121-126. http://dx.doi.org/10.1002/fam.790

Mah, T., \& Song, G. (2010a). Investigation of the Contribution of Garment Design to Thermal Protection. Part 1: Characterizing Air Gaps using Three-dimensional body Scanning for Women's Protective Clothing. Textile Research Journal, 80, 1317-1329. http://dx.doi.org/10.1177/0040517509358795

Mah, T., \& Song, G. (2010b). Investigation of the Contribution of Garment Design to Thermal Protection. Part 2: Instrumented Female Mannequin Flash-fire Evaluation System. Textile Research Journal, 80, 1473-1487. http://dx.doi.org/10.1177/0040517509358796

Mell, W. E., \& Lawson, J. R. (2000). Heat Transfer Model for Fire Fighter's Protective Clothing. Fire Technology, 36, 39-68. http://dx.doi.org/10.1023/A:1015429820426

Mercer, G. N., \& Sidhu, H. S. (2007). Mathematical modeling of the effect of fire exposure on a new type of protective clothing. ANZIAM, 49, C289-C305.

Mercer, G. N., \& Sidhu, H. S. (2009). A Theoretical Investigation into Phase Change Clothing Benefits for Firefighters under Extreme Conditions. Chemical Product and Process Modeling, 4(3), http://dx.doi.org/10.2202/1934-2659.1349

Modest, M. F. (2003). Radiative Heat Transfer (2nd ed.), New York, NY: Academic Press.

National Fire Protection Association. (2007). NFPA 1971 Standard on Protective Ensemble for Structural Fire Fighting, Quincy, Massachusetts. 
Patankar, S. V. (1980). Numerical Heat Transfer and Fluid Flow. Washington, DC: Taylor \& Francis.

Pennes, H. H. (1948). Analysis of tissue and arterial blood temperatures in resting human forearm. Applied Physiology, 1, 93-122.

Sawcyn, C. M. J., \& Torvi, D. A. (2009). Improving Heat Transfer Models of Air Gaps in Bench Top Tests of Thermal Protective Fabrics. Textile Research Journal, 79, 632-644. http://dx.doi.org/10.1177/0040517508093415

Song, G., Barker, R. L., Hamouda, H., Kuznetsov, A. V., Chitrphiromsri, P., \& Grimes, R. V. (2004). Modeling the Thermal Protective Performance of Heat Resistant Garments in Flash Fire Exposures. Textile Research Journal, 74, 1033-1040. http://dx.doi.org/10.1177/004051750407401201

Song, G., Chitrphiromsri, P., \& Ding, D. (2008). Numerical Simulation of Heat and Moisture Transport in Thermal Protective Clothing under Flash Fire Conditions. International Journal of Occupational Safety and Ergonomics, 14, 89-106. http://dx.doi.org/ciop/pl/25866

Takata, A. N., Rouse, J., \& Stanley, T. (1973). Thermal analysis program. Illinois Institute of Technology, Chicago.

Talukdar, P., Torvi, D. A., Simonson, C. J., \& Sawcyn, C. M. J. (2010). Coupled CFD and Radiation Simulation of Air Gaps in Bench Top Protective Fabric Tests. International Journal of Heat and Mass Transfer, 53, 526-539. http://dx.doi.org/10.1016/j.jheatmasstransfer.2009.04.041

Tan, Y., Crown, E. M., \& Capjack, L. (1998). Design and Evaluation of Thermal Protective Flightsuits. Part I: The Design Process and Prototype Development. Clothing and Textiles Research Journal, 16, 47-55. http://dx.doi.org/10.1177/0887302X9801600106

Torvi, D. A. (1997). Heat Transfer in Thin Fibrous Materials under High Heat Flux Conditions (Doctoral dissertation). University of Alberta, Edmonton, Alberta.

Torvi, D. A., \& Dale, J. D. (1999). Heat Transfer in Thin Fibrous Materials under High Heat Flux. Fire Technology, 35, 210-231. http://dx.doi.org/10.1023/A:1015484426361

Torvi, D. A., \& Threlfall, T. G. (2006). Heat Transfer Model of Flame Resistant Fabrics during Cooling After Exposure to Fire. Fire Technology, 42, 27-48. http://dx.doi.org/10.1007/s10694-005-3733-8

Torvi, D. A., Dale, J. D., \& Faulkner, B. (1999). Influence of Air Gaps on Bench Top Test Results of Flame Resistant Fabrics. Fire Protection Engineering, 10, 1-12. http://dx.doi.org/10.1177/104239159901000101

Weaver, J. A., \& Stoll, A. M. (1969). Mathematical Model of Skin Exposed to Thermal Radiation. Aerospace Medicine, 40, 24-30.

Zhu, F., \& Zhang, W. (2009). Modeling Heat Transfer for Heat-resistant Fabrics Considering Pyrolysis Effect under an External Heat Flux. Fire Sciences, 27, 81-96. http://dx.doi.org/10.1177/0734904108094960

\section{Copyrights}

Copyright for this article is retained by the author(s), with first publication rights granted to the journal.

This is an open-access article distributed under the terms and conditions of the Creative Commons Attribution license (http://creativecommons.org/licenses/by/3.0/). 